\title{
Expo Ciencia Granada 2015
}

El día 30 de septiembre del 2015 se llevó a cabo la expo ciencia territorial de Granada en la Plaza de la Independencia de 8 am a 3 pm, estuvo presidida por autoridades de las distintas instituciones de gobierno como: Alcaldía, CONICYT, CNU y MINED.

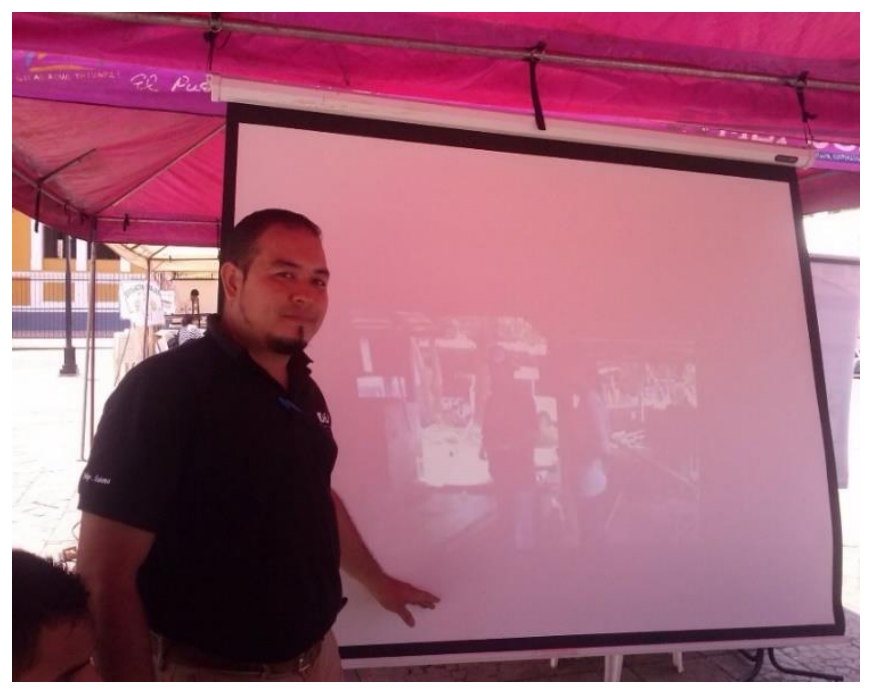

Figura 1. Proyecto: Diagnóstico Participativo del municipio de Santo Domingo y Propuestas de Intervención

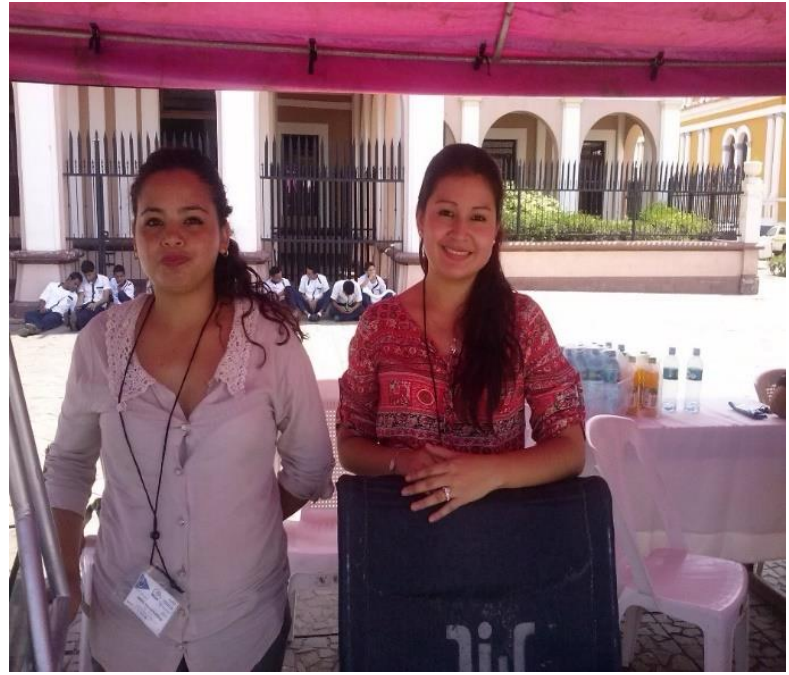

Figura2. Proyecto: Cuna Térmica (CALIN).

Estudiantes del Instituto Politécnico de la Salud

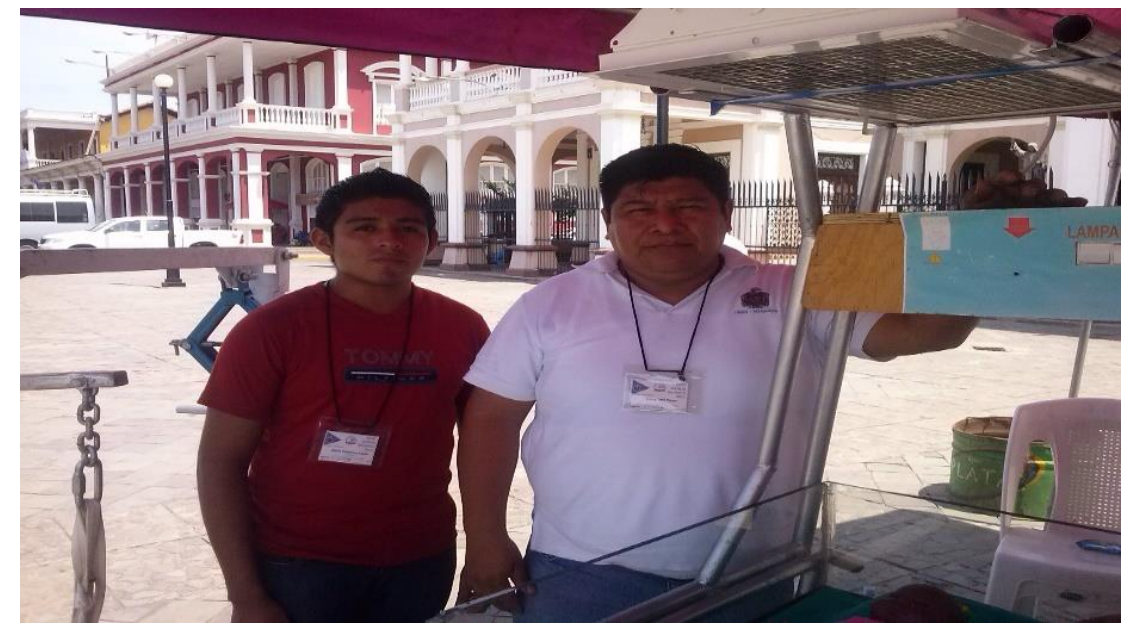

Figura 3. Proyecto: Cuna Térmica (CALIN). Estudiante y docente del Instituto Politécnico de la Salud 


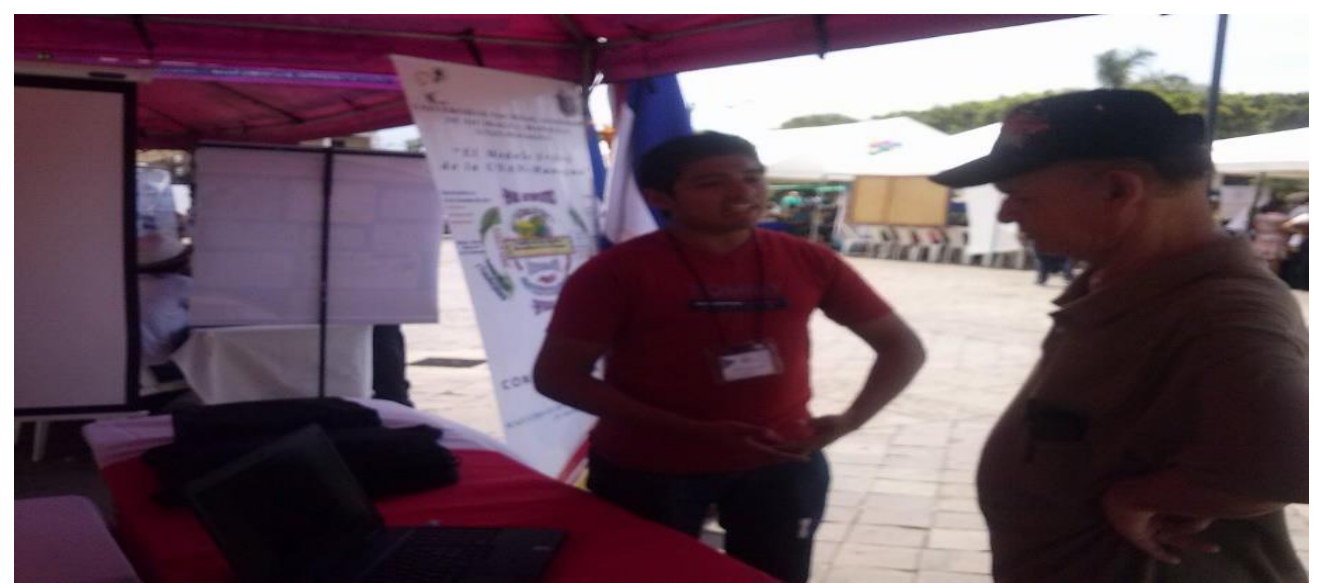

Figura 4. Proyecto: Glucómetro Inteligente (GISP). Estudiante y docente del Instituto Politécnico de la Salud

\section{LISTADO DE PROYECTOS}

\begin{tabular}{|c|c|c|c|c|c|}
\hline \multicolumn{6}{|c|}{$\begin{array}{l}\text { INSTITUTO POLITÉCNICO DE LA SALUD } \\
\text { Coordinador: Trinidad Díaz }\end{array}$} \\
\hline 1 & Cuna Térmica (CALIN) & $\begin{array}{l}\text { Brindar mayor cobertura en } \\
\text { la atención materno infantil } \\
\text { en las salas de parto y } \\
\text { Neonatos }\end{array}$ & Salud pública & 1 & Judith Amara Buitrago \\
\hline 2 & $\begin{array}{l}\text { Silla Ergonómica (LIVE } \\
\text { CHAIR) }\end{array}$ & $\begin{array}{l}\text { Elaborar un nuevo modelo } \\
\text { de Silla Ergonómica que } \\
\text { cumpla los requerimientos } \\
\text { básicos de ergonomía". }\end{array}$ & Salud pública & 2 & Josseling Lara Muñoz \\
\hline 3 & $\begin{array}{l}\text { Glucómetro Inteligente } \\
\text { (GISP) }\end{array}$ & $\begin{array}{l}\text { Brindar mayor cobertura en } \\
\text { el control y manejo de la } \\
\text { diabetes mellitus en la } \\
\text { población nicaragüense en } \\
\text { todos y cada uno de los } \\
\text { sectores del país }\end{array}$ & Salud pública & 3 & Denis Francisco López \\
\hline \multicolumn{6}{|c|}{ FACULTAD DE HUMANIDADES Y CIENCIAS JURÍDICAS } \\
\hline 4 & $\begin{array}{l}\text { Diagnóstico Participativo } \\
\text { del municipio de Santo } \\
\text { Domingo y Propuestas de } \\
\text { Intervención - }\end{array}$ & $\begin{array}{l}\text { Desarrollar propuestas con } \\
\text { enfoque participativo para } \\
\text { la intervención y el } \\
\text { bienestar comunitario }\end{array}$ & $\begin{array}{l}\text { Comunidad y } \\
\text { Desarrollo }\end{array}$ & 4 & Felipe Mairena Montiel \\
\hline \multicolumn{6}{|c|}{ FACULTAD DE CIENCIAS MÉDICAS } \\
\hline \multirow[t]{2}{*}{5} & Levanta Paciente & $\begin{array}{l}\text { Ayudar a levantar los } \\
\text { paciente que tienen } \\
\text { problemas de movilidad }\end{array}$ & Salud Pública & 5 & Sofía del Carmen Lacayo \\
\hline & & & & 6 & Hellen Rebeca Juárez \\
\hline
\end{tabular}

